\title{
Diálogos interdisciplinares e experiências projetuais
}

\section{Interdisciplinary Dialogues and Design Experiences}

\author{
LEHMKUHLL, Luciene \\ Universidade Federal da Paraíba I lucilehmkuhl@hotmail.com \\ PEREIRA, Leandro Lopes \\ Universidade Federal da Paraíba I Ipereira000@gmail.com
}

\begin{abstract}
Resumo
Este texto propõe discutir questões teórico/ metodológicas concernentes à projetação em Design, com o aporte da Estética e do Design Thinking, buscando relatar experiência interdisciplinar envolvendo as disciplinas Projeto de Produto 1 e Estética no Curso de Design da Universidade Federal da Paraíba. A opção pelo diálogo interdisciplinar nos leva a refletir acerca das relações entre designers, produtos e seus usuários. Dos resultados, foi possível observar que a tarefa de estimular jovens estudantes a fazerem uso consciente da função estética dos produtos no ato de projetação, obteve êxito e gerou novas iniciativas.

\section{Abstract}

Thispaperaimstodiscusstheoretical/methodological issues concerning the Design process. Grounded by aesthetics and Design Thinking, the study intends to report our interdisciplinary experience involving the courses of Product Design and Aesthetics in the Design Course at Federal University of Paraiba. The option for interdisciplinary dialogue leads us to think about the relationship between designers, products and users. As a result, we could observe that the task of stimulating young Design students to have an aware use of the aesthetic function for the product in the Design process has been successful, thus encouraging them to take action.
\end{abstract}

Palavras-chave:Interdisciplinaridade; projetação; Estética; experiência.

Key-words: Interdisciplinary; Design process; Aesthetic; experience. 


\section{DIÁLOGOS DISCIPLINARES NA FORMAC̣ÃO DE DESIGNERS}

Uma compreensão mais ampla sobre a natureza da atividade de projetar produtos, nos leva a perceber uma trama de relações complexas entre designers e profissionais de outras áreas de formação. Por vezes, estas relações se apresentam de forma hierárquica, levando o designer a atuar em etapas isoladas, submetendo-se às decisões tomadas por outros profissionais com funções dominantes. Em outras situações, o designer pode assumir uma função mais relevante, atuando como mediador, coordenador ou gestor do projeto. Em outros contextos, o designer pode assumir uma função estratégica, com maior abrangência e relevância da sua atuação.

Observa-se que nos três cenários colocados, os designers necessitam da capacidade de dialogar com os demais profissionais, em condições de atender e solicitar demandas, compreender contextos, mediar e estimular o diálogo e ainda, gerir pequenas e grandes equipes de trabalho em atividade projetual. Nesse sentido, há a necessidade de percorrer os caminhos da teoria e da prática, por meio de atividades projetuais que permitam reflexões construtivas sobre tais relações para que se desenvolva, entre tantas outras, a capacidade de analisar e consequentemente adequar-se aos diferentes contextos de projeto.

Com estes entendimentos, o presente texto apresenta análises e discussões a partir das experiências desenvolvidas em projeto interdisciplinar voltado aos meios para alcançar resultados que favoreçam simultaneamente o exercício de reflexões e práticas. Interessados em refletir teórica e metodologicamente acerca das experiências de projetação no desenvolvimento de produtos de Design e unidos pela preparação das disciplinas Projeto de Produto I e Estética, que ministramos no curso de Design da UFPB, mergulhamos em debates acerca da projetação e análise de produtos. Decidimos, então, unir esforços e lançar aos estudantes e a nós mesmos o desafio de estabelecer pontes e reflexões entre ambas disciplinas a partir da tarefa de projetar produtos de Design em diálogo com as questões estéticas ${ }^{1}$.

No Curso de Design da UFPB, a área projetual inicia-se com as disciplinas Projeto Básico (1 e 2), nas quais são estudados os métodos para desenvolvimento de produtos. A partir da disciplina Projeto de Produto 1, são propostos temas e diferentes sistemáticas de trabalhos, comportando o estudo e a experimentação de métodos e ferramentas de projeto, para que os estudantes sejam expostos à situações próximas àquelas encontradas na vida profissional, combinando condicionantes como prazos, aspectos mercadológicos e de produção, além dos aspectos teóricos e subjetivos ligados aos produtos com a finalidade de desenvolver a capacidade de reflexão. Por outro lado, a disciplina Estética, neste

1 Este texto foi desenvolvido a partir de trabalho apresentado no IDEMi 2015, desta maneira, as partes do texto anteriormente publicadas nos anais são acrescidas de informação extra como relatos, imagens e reflexões do processo e dos resultados do experimento, cuja conclusão se deu posteriormente ao evento. 
curso, encontra-se vinculada a outras disciplinas, como História da Arte, História do Design, Arte e Design Contemporâneos e Design Brasileiro. Busca-se, com estas disciplinas, contribuir na formação de repertório e no desenvolvimento de capacidade crítica dos estudantes, que poderão fazer uso dos conhecimentos relativos aos campos da história e da Estética nas pesquisas e nas análises de produtos, de público consumidor, expectativas dos usuários e do mercado, bem como, em todo processo de projetação, para a concepção de produtos.

\section{A PERCEPC̣ÃO HUMANA NA PROJETAC̣ÃO}

A principal tarefa do designer é definida por Löbach (2001, p. 64) como a dedicação à "função estética dos produtos, atendendo às principais condições de percepção do homem", o autor defende que "[...] para a saúde psíquica do ser humano é preciso que o entorno de objetos produzidos artificialmente seja otimizado de acordo com as características perceptivas do ser humano" (LÖBACH, 2001, p. 62), que "é preciso levar em conta as necessidades do usuário na determinação das funções estéticas e simbólicas dos produtos" (LÖBACH, 2001, p. 57), e indica um caminho ao propor que caso o designer

\footnotetext{
[...] tivesse acesso a dados mais objetivos sobre as necessidades estéticas e simbólicas do futuro usuário, ou se tivesse a oportunidade de investiga-las diretamente, por meio de entrevistas ou testes, poderia então estabelecer os aspectos estéticos dos produtos segundo critérios racionais (LÖBACH, 2001, p. 56).
}

As afirmativas do autor suscitam questões que conduzem nossas inquietações neste texto. Como professores, em meio à tarefa de formar designers e faze-los valorizar a reflexão e o fazer simultaneamente nos perguntamos, ao acompanharmos a proposição de Löbach (2001), até que ponto podem ser obtidos "dados mais objetivos" sobre as necessidades estéticas e simbólicas dos usuários? E também, como poderá o designer estabelecer aspectos estéticos do produto segundo critérios "racionais"? Estas questões de caráter ontológico, epistemológico e também prático surgem em meio a preocupação em fazer dialogar a reflexão estética com o desenvolvimento de projetos de produtos. A elaboração dos painéis visuais pelas equipes durante o desenvolvimento dos projetos nos permitiu perceber o papel do campo estético na projetação, especialmente ao discutirmos as funções atribuídas aos produtos.

Faggiani (2006) sustenta que os objetos, enquanto elementos da cultura material, possuem funções que ultrapassam o cumprimento dos requisitos funcionais e técnicos, de modo a envolver fatores simbólicos, psicológicos e afetivos. Estes, "não detém significados fixos e únicos" (FAGGIANI, 2006, p. 67). A autora ressalta que, devido à estreita relação com a vida dos consumidores/ usuários, os objetos possuem a capacidade de representar muito além da sua própria materialidade e funcionalidade. São, portanto, essas relações os 
responsáveis pela conquista dos “[...] significados que podem estar relacionados aos aspectos funcionais do produto, mas principalmente aos valores simbólicos a ele atribuídos. [E] ao criar um objeto, o designer se defronta com problemas mais amplos do que o a criação e produção do mesmo" (FAGGIANI, 2006, p. 65).

Ampliando o debate, Forty (2007) apresenta um posicionamento mais racional quanto a dicotomia entre os aspectos visuais e funcionais dos objetos. Para ele, "longe de ser uma atividade artística, neutra e inofensiva, o Design, por sua própria natureza, provoca efeitos muito mais duradouros do que os produtos efêmeros da mídia porque pode dar formas tangíveis e permanentes às ideias sobre quem somos e como devemos nos comportar" (FORTY, 2007, p. 12).

Para Forty (2007), a palavra Design abrange dois sentidos que são indissociáveis. O primeiro refere-se à "aparência das coisas", restringindo-se ao julgamento da beleza, enquanto que o segundo reporta-se ao projeto para a "produção de bens manufaturados". Para o autor "a aparência das coisas é, no sentido mais amplo, uma consequência das condições da sua produção" (FORTY, 2007, p. 12). É possível estender esta definição às necessidades dos usuários, uma vez que os processos para produção são desenvolvidos e incrementados para viabilizar a materialização de objetos projetados para a satisfação humana.

Para Faggiani (2006, p. 68), quando o discurso de Design é reduzido à oposição entre arte e tecnologia, acaba por refletir certa "ignorância com relação aos significados e valores que aparecem na relação mútua entre estas duas áreas, e que são transpostos nos produtos que constituem nossa cultura material". Por isso, para a autora o designer tem como atribuição a criação de produtos a partir da percepção do comportamento, dotando os objetos de significados para que estes não sejam vistos como algo "neutro e separado de seu contexto social e funcional. Esta maneira de ver o design modifica o panorama conceitual com relação à sua responsabilidade junto à sociedade e à sua cultura material" (FAGGIANI, 2006, p. 68). Sendo assim, a sua concepção de Design permeia desde os campos subjetivos da percepção humana até os mais concretos no desempenho das funções práticas de uso. O autor considera também os impactos da globalização no Design ao afirmar que, "apesar de todas estas previsões positivas a partir da globalização, é de extrema importância que antes de qualquer coisa se leve em conta fatores culturais e sociais (língua, cultura, valores), simbólicos, atitudes e preferências locais antes de oferecer um produto ou serviço" (FAGGIANI, 2006, p. 62).

Ainda sobre a percepção humana, Löbach (2001, p. 157) defende o enfoque naquilo que denomina como "comunicação estética", sistema no qual ocorrem a produção e o consumo estéticos, sendo o designer o emissor, o usuário o receptor e o produto o meio/elemento da comunicação. No entanto, o aspecto de interesse dessa comunicação estética reside na relação entre 
pessoas e objetos e não no objeto em si, nem mesmo no trabalho exclusivo do designer. Vale lembrar o pensamento de Bonsiepe (1997, p. 15), para quem o "design se orienta à interação entre usuário e artefato [sendo que] o domínio do design é o domínio da interface". O autor nos lembra ainda que o "design está linguisticamente ancorado no campo dos juízos", sendo assim, podemos relaciona-lo aos juízos estéticos, quando Haar (2000, p. 33) nos faz lembrar que para Kant em sua Terceira Crítica,

\begin{abstract}
[...] as questões de gosto ou de beleza não se atêm a qualquer saber: não são um juízo 'determinante', isto é, um juízo pelo qual aplicamos um conceito a um objeto com a finalidade de ampliar nosso conhecimento. São, pelo contrário, um juízo 'reflexionante', pelo qual encontramos um elo necessário entre uma representação e um sentimento de prazer.
\end{abstract}

Se tomarmos o gosto como julgamento estético, chegaremos ao prazer da contemplação que consiste na experiência do encontro com uma obra em sua multiplicidade de sentidos. Tomamos a reflexão de Korichi (2007, p. 189), ao apresentar e discutir os conceitos fundamentais da Estética, fazendo lembrar que "o gosto coloca em jogo a dimensão sensorial (o efeito) da aparição daquilo que podemos qualificar como belo e o julgamento sobre o qual esse prazer (ou desprazer) pode se fundamentar". Assim, nos encontramos entre um gosto espontâneo, que não exprime necessariamente um julgamento, e um gosto refletido, que exige aprendizagem e se refere a regras pré-estabelecidas. Para a autora, a antinomia existente entre a espontaneidade e a lógica é "[...] uma mistura indissolúvel de sensível e inteligível que constitui o domínio próprio da estética" (KORICHI, 2007, p. 221).

Este imenso campo, no entanto, abrange diferentes aspectos indicados por Löbach (2001) como a "estética do objeto" (características configurativas) e a "percepção estética" (processo de significação da aparência estética), sendo importante a identificação dos "valores estéticos" atribuídos aos produtos e das normas estéticas fixadas e posteriormente reconhecidas nos produtos pelos usuários. Acessar este entremeio de informações é tarefa passível de realização, desde que chegue ao designer o resultado dos dados levantados acerca das opiniões dos usuários, entre as quais devem constar suas manifestações de gosto e de apreciação estética do produto e seu uso. Esta tarefa de coleta e análise de dados é denominada por Löbach (2001, p. 187) como "estética empírica", para a qual ele indica possibilidades de métodos de pesquisa que auxiliariam no conhecimento dos valores esperados pelo usuário, aos quais o designer pode adicionar seus próprios conceitos sobre valor estético.

Diante deste espectro de complexas relações entre a multissensorialidade da percepção humana, o ato de conceber produtos a partir das expectativas de seus possíveis usuários e, ainda, as condicionantes apresentadas pelos processos de produção industrial, reportamo-nos à formação dos futuros designers e à tentativa de prepara-los para situações com as quais irão deparar- 
se no exercício da profissão.

\section{RELAÇÕES ENTRE TEORIAS E PRÁTICAS NAS ATIVIDADES PROJETUAIS}

Com o objetivo de fortalecer os aspectos teóricos, pertinentes ao campo estético de caráter especialmente subjetivo, envolvidos na projetação, elaboramos planejamentos de forma a sincronizar os conteúdos das disciplinas Projeto de Produto 1 e Estética, a partir de uma iniciativa interdisciplinar. Esta experiência trouxe aos professores e estudantes uma possibilidade de abordagem que amplia a visão sobre as relações entre os métodos projetuais e aspectos atribuídos, muitas vezes, ao campo restrito das disciplinas. $\mathrm{Na}$ experiência realizada percebemos que as contribuições da estética, enquanto campo de conhecimento e disciplina especifica da matriz curricular, podem ser muito maiores, quando aplicados de forma adequada e aprofundada em diálogo com as disciplinas projetuais.

Na proposta que encampamos, desde o momento em que se definiu o cenário para o desenvolvimento de produto, os estudante foram provocados a pesquisar, refletir e posicionar-se a partir de um julgamento técnico aliado às suas próprias percepções e aquelas advindas dos usuários. Trata-se de tira-los da chamada "zona de conforto", que pressupõe propostas fechadas, cabendo aos estudantes apenas definir aspectos limitados sobre o cenário a ser utilizado no desenvolvimento do produto. Nas atividades propostas pela disciplina Projeto 1, os estudantes foram estimulados a aplicar os princípios do Design universal, entretanto, não foi estabelecida uma categoria específica de produto para a turma, sendo dada liberdade para os estudantes escolherem o tipo de produto.

A atividade projetual possui como característica um grande espectro de ações. Tais ações serão mais ou menos necessárias e exploradas em razão das características do projeto, sua finalidade e o contexto de sua realização. Ao considerarmos o contexto industrial, em infraestrutura adequada, será possível desdobrar as ações necessárias, percorrendo-se inclusive formas complexas de pesquisa e desenvolvimento. Já um projeto realizado em contexto mais simples, em universo menor, exige menos desdobramentos em etapas projetuais. Esta mesma relação pode ser observada no ensino quando ponderamos o incremento de conteúdos na medida em que os estudantes avançam em seus cursos.

Atividades projetuais em períodos iniciais do curso devem ser mais simplificadas, explorando-se apenas as competências e habilidades já adquiridas ou aquelas que estão em desenvolvimento, sendo interessante, sempre que possível, projetar contextos e cenários futuros, para que os estudantes consigam relacionar os conteúdos (conhecimentos) e suas aplicações. Estas colocações nos permitem compreender que a importância atribuída às disciplinas projetuais nos cursos de Design somente é percebida e consolidada com o aporte das 
demais disciplinas e conhecimentos específicos.

Costuma ser usual em disciplinas de projeto, que seja proposto um grande tema para que os estudantes tenham um assunto em comum para construção e compartilhamento de conhecimentos. Os projetos aqui apresentados foram condicionados à aplicação dos princípios do Design universal (Uso equitativo; Uso flexível; Uso simples e intuitivo ; Informação perceptível; Tolerância ao erro; Esforço físico mínimo; Tamanho e espaço para aproximação e uso. NCSU, 1997.), não sendo determinado uma categoria específica de produtos. Uma vez esclarecida a proposta, foram iniciadas as discussões em dois caminhos, o primeiro de aprofundamento sobre o tema, e o segundo para a definição do método projetual adequado à proposta.

A partir de uma análise sobre quais métodos projetuais seriam melhor aplicados a este contexto, encontramos na publicação Design Thinking, de Vianna et al. (2012), um caminho metodológico. Entendemos que este método poderia nos oferecer melhores condições para a realização das atividades e assim atingirmos os objetivos propostos, principalmente, devido ao tratamento especial dado ao público alvo, que atua com papel decisivo, desde as fases iniciais do projeto até as finais, quando é materializado e implementado. Entretanto, este método permite ser complementado com ferramentas de outros métodos em todas as suas etapas visando resultados mais aprofundados. A abordagem do Design Thinking, proposta por Vianna et al. (2012), é estruturada em três grandes etapas denominadas por "Imersão", "Ideação" e "Prototipação". Na primeira etapa, "Imersão", ocorre a captura ou coleta de informações acerca do comportamento do público alvo. Para tanto, são lançados os seguintes questionamentos: "O que as pessoas falam? Como agem? O que pensam? Como se sentem?" (VIANNA et al. 2012, p. 36). No tratamento destas informações, ocorrem processos de análise e síntese, de modo a possibilitar a transformação (enquanto melhoria) e a preparação para as etapas subsequentes, "ideação" e "prototipação". Na proposta aplicada em sala de aula, a primeira etapa foi ampliada com algumas ferramentas de análise sugeridas por Löbach (2001), como análises de produtos, de sistemas funcionais, de uso, dos materiais e dos processos de fabricação e da configuração visual) e Baxter (1998), como painéis semânticos e análise de mercado, permitindo aos estudantes autonomia na escolha das ferramentas a serem combinadas.

Em meio às discussões de aula e orientações, o texto de Löbach (2001), especialmente os capítulos 4 e 9, se tornou leitura obrigatória e suas ideias pautaram as ações da disciplina Estética na busca de interação com o desenvolvimento dos projetos, no momento em que nos deparamos com aspectos de ordem estética presentes nas decisões a serem tomadas para a configuração visual dos produtos. Assim, ao estudo dos conceitos fundamentais do campo da estética, como o belo, o sublime, o gosto, a crítica, o julgamento e a arte, foram acrescidos os conceitos de cultura, de popular e erudito, com o auxílio dos quais foram explorados o conhecimento e avaliação da percepção dos usuários e o repertório dos estudantes para a realização da 
projetação e configuração visual dos produtos. Em diálogo com autores que discutem História, Arte e Estética (BENJAMIN et al., 2012; DIDI-HUBERMAN, 2013; GOMBRICH, 1999; WARBURG, 2010), propomos a sensibilização dos estudantes por meio da leitura de obras de arte e de produtos de Design visando situar historicamente os conceitos abordados e, consequentemente auxiliar no levantamento, tratamento e sistematização dos dados obtidos para o estudo do público alvo e para a análise de produtos similares e concorrentes.

Quando os estudantes iniciaram a composição de painéis visuais para a organização e análise de dados acerca dos produtos similares e dos possíveis usuários dos produtos que estavam desenvolvendo, as questões levantadas por Löbach (2001) se materializaram como imagens de pessoas, objetos, lugares e atitudes perante os produtos da indústria. Surgiram então questionamentos acerca das escolhas, apresentações e posicionamentos das imagens que melhor ilustrariam as necessidades dos usuários, o problema existente e as possíveis soluções concernentes ao produto em desenvolvimento. Neste processo cada equipe desenvolveu pranchas visuais fazendo uso de recortes, colagens, desenhos, montagens digitais e escrita para expressar suas ideias. Diferentes painéis foram elaborados conforme as discussões se desenvolviam e avançavam nas disciplinas, levando a visíveis alterações nos painéis que se multiplicavam a cada encontro.

Dentre os doze projetos desenvolvidos, para exemplificar a experiência, destacamos cinco trabalhos realizados pelos estudantes em ambas disciplinas, que atenderam de forma mais completa as solicitações iniciais, aqui tratados como projetos 1, 2, 3, 4 e 5, apresentados em suas diversas especificidades.

No projeto 1, de autoria dos estudantes Andeylson David da Silva Pontes e Hyago Nóbrega Dias, foi desenvolvido um "Equipamento de segurança voltado a motociclistas", retrovisor com dispositivo "corta-pipa". Os estudantes realizaram uma interessante coleta de informações acerca da realidade enfrentada por motociclistas nas grandes cidades, por meio de dados estatísticos sobre acidentes e reportagens. Interessante ferramenta utilizada foi o mapa conceitual, que permitiu uma melhor clareza sobre o projeto. Desta forma puderam ser definidas as diretrizes projetais.

Os estudantes apresentaram cinco painéis visuais de estudo do público alvo. No primeiro deles foram escolhidas imagens que representam aspectos desportivos e divertidos no uso de motocicletas, sem referências explícitas ao problema a ser solucionado, a segurança do motociclista. No segundo painel recortes de detalhes de equipamentos demonstram alguma proximidade com o tema do estudo. No terceiro painel é incluída uma imagem (ainda que timidamente) do foco central do problema a ser abordado, a linha de cerol das pipas que causa graves acidentes aos motociclistas. No painel de número 4 esta imagem foi eliminada e foram incluídas referencias as cores mais comumente utilizadas. No painel de número 5 a gama de cores foi ampliada e foram acrescentadas palavras que designam as necessidades dos possíveis 
usuários. Ao ser questionada sobre a decisão de excluir dos painéis a imagem do foco central do problema a ser abordado no projeto, a equipe expressou a importância da inclusão desse tipo de imagem a partir dos debates e questionamentos em sala de aula e tomou a decisão de incluir um painel denominado de Impacto, para mostrar com maior detalhamento os graves ferimentos causados pela linha de cerol. No produto gerado e nas justificativas da equipe para sua produção fica evidente a importância do debate gerado a partir da comparação de imagens nos painéis visuais, especialmente a inclusão das imagens de impacto dos acidentes e situações de uso do cerol.

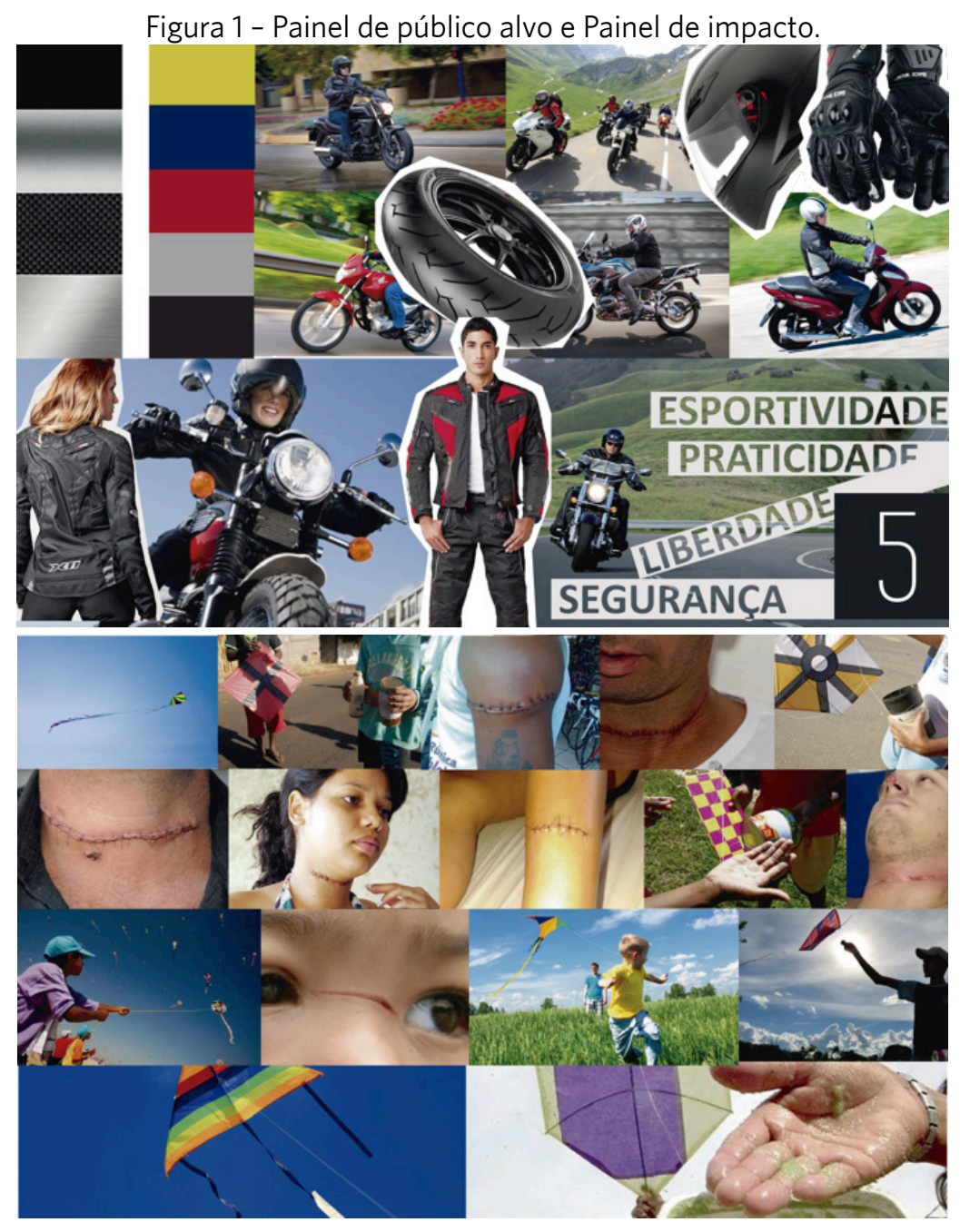

Fonte: Elaborado pelos autores.

Como segundo exemplo apresentamos o projeto 2, "Mobiliário institucional: estante bibliotecária com prateleira deslizante para acesso de usuários com deficiência física", realizado pelos estudantes Gabriel José da Silva, Herik Lucas Costa Seixas e Rafael Victor Ferreira, que propõe uma estante bibliotecária com prateleira deslizante, cuja função é dar acesso e autonomia aos deficientes físicos na disposição do acervo de uma biblioteca. Apesar da padronização de mobiliário e de normas existentes, verificou-se que há uma carência do mercado em moveis dessa natureza que atenda a todos os públicos e leve em consideração o Design universal. A partir dessa necessidade surgiu a possibilidade de solucioná-la através de uma estante com a prateleira móvel 
até o alcance do cadeirante. Foram desenvolvidas várias pesquisas e análises de campo que resultaram em diretrizes projetuais e refinamento do conceito até chegar a solução final. Dentre as pesquisas, destacamos a vivência realizada com o apoio do laboratório do Departamento de Terapia Ocupacional. Esta ação oportunizou aprendizados significativos no sentido de os estudantes se colocarem na situação dos usuários cadeirantes. Também foi possível ampliar a abrangência dos usuários para pessoas de baixa estatura. Outra importante fonte de pesquisa foram as normas técnicas referentes a estes espaços, bem como as recomendações ergonômicas e antropométricas. Como resultado deste projeto, destacamos a simplicidade com que o problema foi solucionado, de forma integrada com a configuração visual das demais estantes da biblioteca.

Figura 2 - Mapa mental; fotografias de vivencia na biblioteca; modelos digitais.
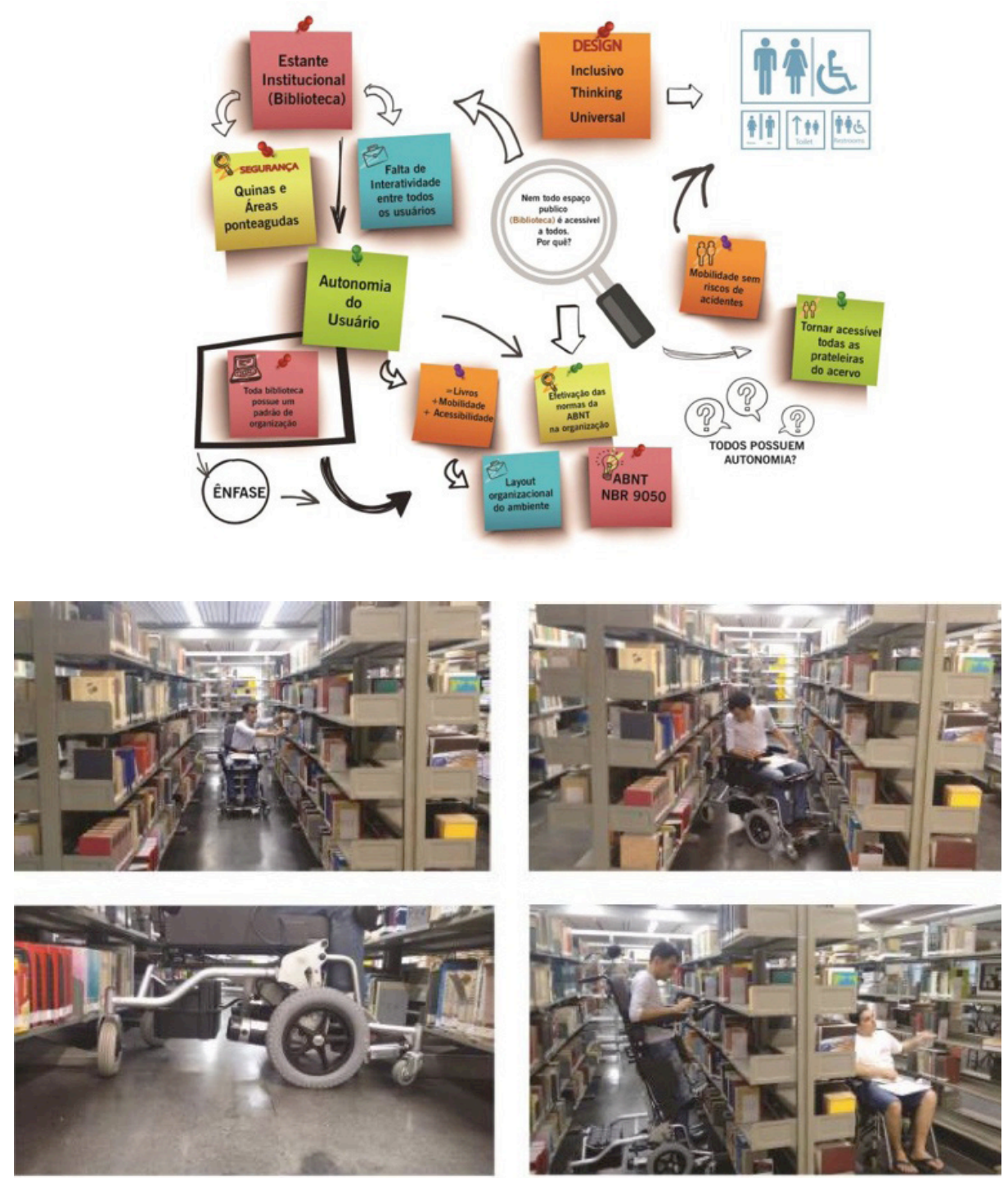

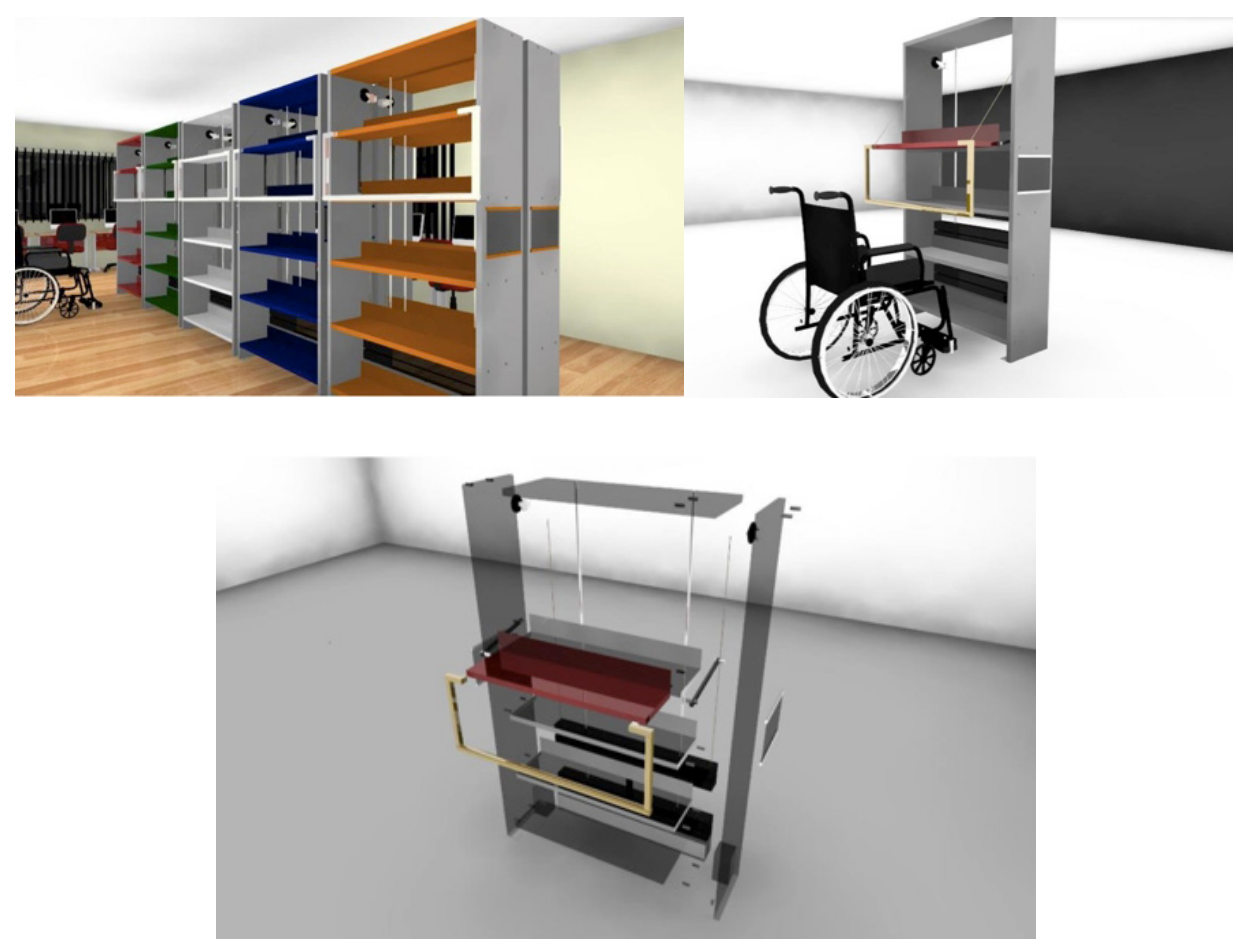

Fonte: Elaborado pelos autores.

O projeto número 3 apresenta a inclusão de uma discussão de gênero e diversidade no projeto a partir da elaboração dos painéis. A equipe formada por Isabelle Karoline Carvalho do Nascimento e Felipe Douglas Pereira Santos, que propôs projetar um "Kit de maquiagem para pessoas com movimentos restritos nas mãos", apresentou um painel inicial contendo apenas imagens de mulheres maquiadas, sendo os homens mostrados apenas como coadjuvantes na representação das deficiências físicas.

Após discussões em sala de aula, o painel foi reelaborado e ganhou imagens de homens e mulheres usando maquiagem ou na ação de maquiagem, ampliando assim o espectro do público a ser atingido (alterando o título inicial que fazia alusão a utilização exclusivamente por mulheres), em consonância com a proposta do projeto. Esta ampliação levou a decisão do conceito do produto, cujo nome masculino foi utilizado sem problemas e restrições pela equipe, atingindo adequadamente o objetivo proposto. 
Figura 3 - Painel de público alvo 1 e 2.
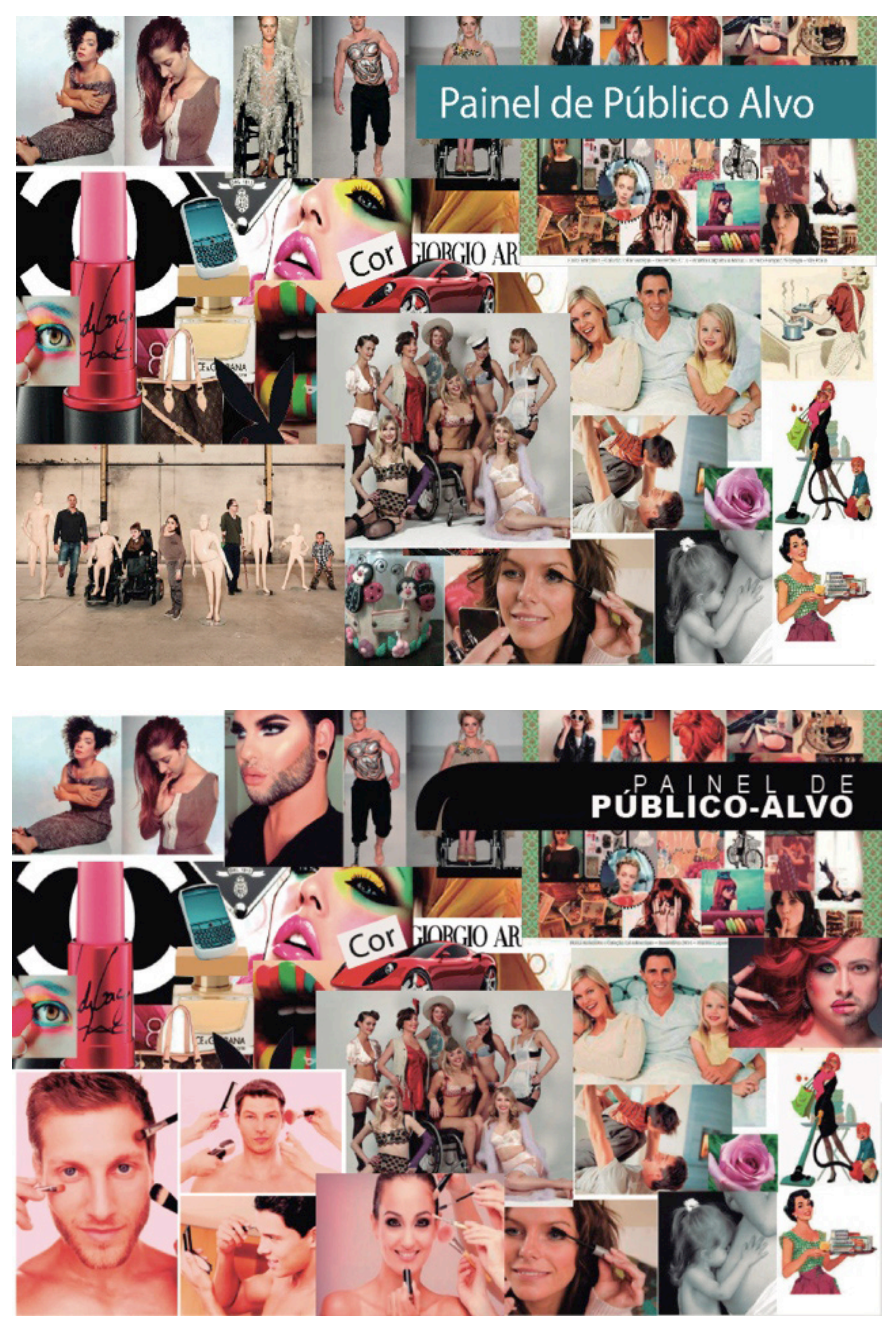

Fonte: Elaborado pelos autores.

O projeto número 4, dos estudantes Alisson Santos de Oliveira e Andreza Silva de Souza, propôs o desenvolvimento de um "Acômodo para acompanhantes de pacientes hospitalizados" e demonstra a aplicação digital de imagens colhidas na web para apresentar os produtos similares existentes no mercado. Foi inicialmente elaborado um painel que continha um número amplo de exemplares, no entanto, focados no tipo de mobiliário próprio de ambientes hospitalares. Nas aulas e orientações a equipe foi estimulada a buscar novas imagens e explorar cores, texturas, materiais e formas que melhor caracterizam cada objeto existente no mercado. Um segundo painel foi elaborado com alteração nas cores dos mobiliários, incluindo o branco e o verde como cores presentes nos ambientes estudados. No terceiro painel foram incluídos os materiais comumente utilizados. No quarto painel foram acrescentados itens com referências a mobiliários que expressam conforto, comodidade e bem estar, mas não necessariamente presentes em ambientes hospitalares. Percebe-se neste painel ampliação da gama de cores, referencia aos materiais e variedade nas referencias formais.

A realização de análises foi feita in loco para que o contexto observado estivesse mais próximo à realidade. Para tanto, a equipe buscou meios de acesso 
à hospitais públicos tomando o cuidado de preservar suas identidades, assim como dos usuários, apenas tomando anotações a partir do que foi observado, uma vez que o objetivo era apenas identificar as formas de acômodo. Deste modo os estudantes puderam observas as condições enfrentadas pelos acompanhantes dos pacientes e quais são os produtos/objetos disponibilizados, quando são de fato disponibilizados, pois em muitos casos isso não ocorre e os acompanhantes dos pacientes devem providenciar seus próprios acômodos. A partir destas observações foram realizadas buscas por produtos similares disponíveis no mercado para que estes fossem comparados por meio de análises. Um dos maiores desafios colocados aos estudantes neste projeto foi o equacionamento das questões referentes ao produto ideal, especialmente ao que se refere ao conforto, e aos custos que o novo produto poderia representar à administração pública. Por esta razão, também fez-se necessária uma pesquisa mais detalhada sobre os materiais de baixo custo que atendessem à necessidade de conforto. Outro ponto de destaque foram as pesquisas sobre os processos de realização de pregões e licitação pública para que se pudesse compreender melhor as razões que configuram o contexto apresentado.

Figura 4 - Painel de similares 1 e 4.
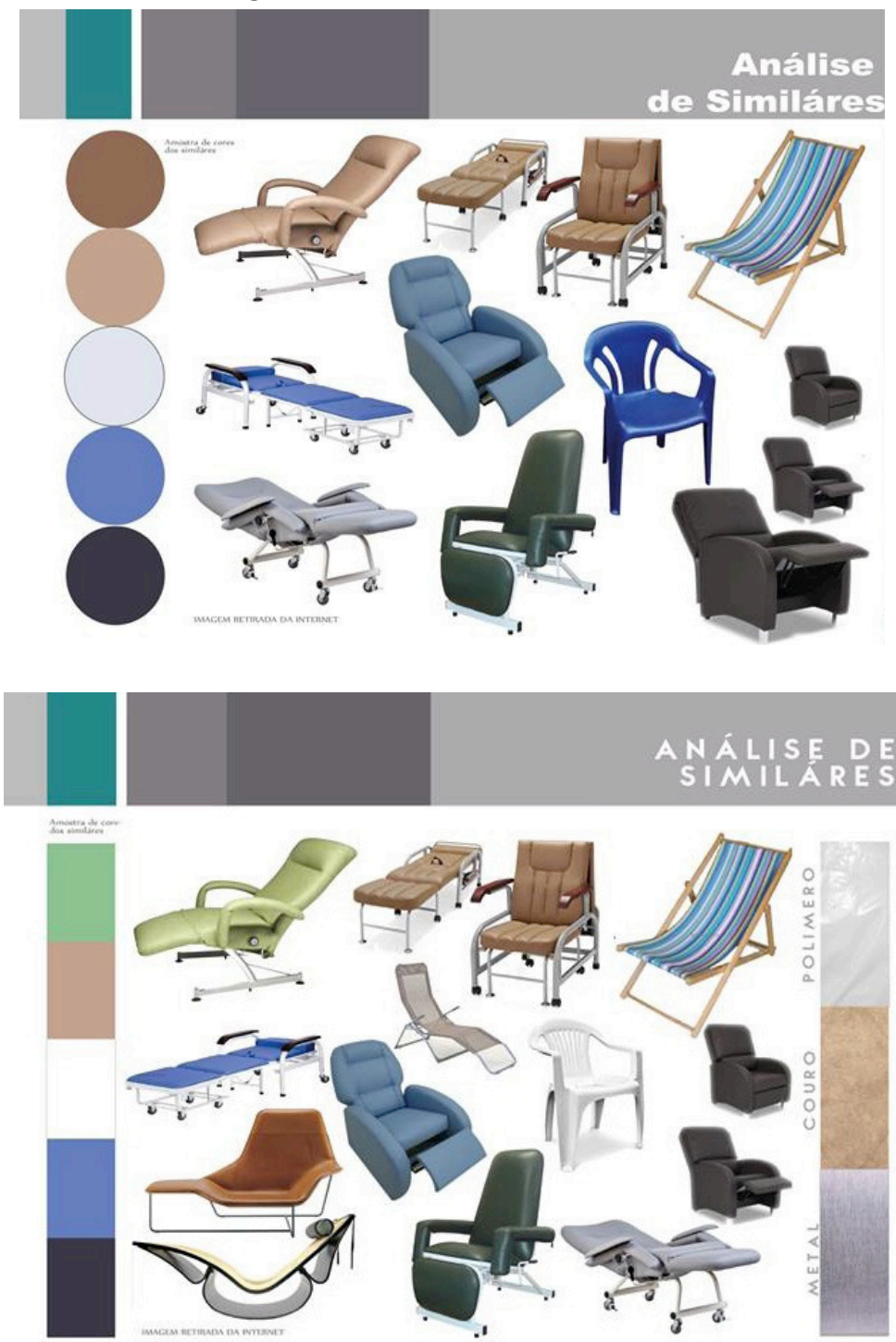

Fonte: Elaborado pelos autores. 
Ainda no projeto número 4 os painéis de público alvo também sofreram consideráveis alterações a partir das discussões nas disciplinas. De uma primeira proposta que agrupava quase que aleatoriamente pessoas de diferentes idades, em diferentes situações, passaram a um refinamento e detalhamento das características dos usuários e do ambiente estudado, incluindo-se segmentação de faixa etária, situação focada no ambiente hospitalar, com seleção apurada de imagens e inclusão de palavras que indicam características a serem consideradas no estabelecimento dos requisitos e parâmetros.

A partir do refinamento das questões obtidos com a construção do mapa mental na disciplina de Projeto 1, foram definidos painéis de cores e de materiais, refinados a partir de levantamento prévio, presentes nos painéis de similares e de público alvo. Como finalização da etapa apresentada na disciplina de Estética, foi apresentada uma prancha com a geração de alternativas desenhadas manualmente, apontando também as cores e materiais de possível utilização. Vale destacar que a alternativa escolhida está diretamente relacionada com a inclusão de diferentes exemplos de mobiliários nos painéis de produtos similares, sendo destacada pela equipe a contribuição da reflexão estética para a geração e escolha da alternativa mais adequada.

Figura 5 - Mapa mental e geração de alternativas.

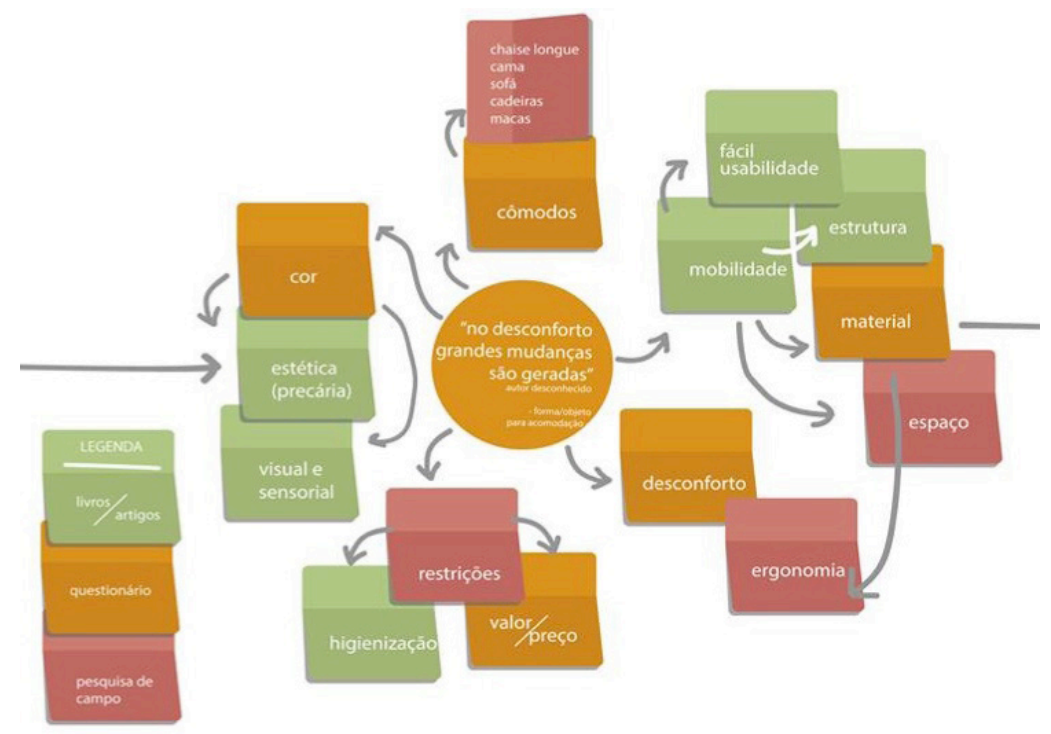

Fonte: Elaborado pelos autores.

O projeto 5, de Eduardo Lima de Souza e Karla Maria Moreno Matos, propõe o desenvolvimento de um produto "com novo conceito de sentar", para uso no espaço de vivencia do campus universitário no qual o curso de Design está alocado. Destacamos na elaboração dos painéis deste grupo a inclusão de imagens tomadas in loco e não apenas capturadas na web ou recortadas de revistas. O tema, o local e o problema escolhidos exigiram e permitiram a pesquisa de campo, levando a equipe a fotografar espaços e pessoas no próprio campus universitário, em diferentes posições e maneiras de sentar e estar, em diferentes momentos. Observa-se nos sete painéis apresentados, a 
transformação nas imagens utilizadas. No primeiro são todas coletadas na web e pouco significativas das reais condições de uso do espaço ao qual o projeto se destinava. Após as discussões em sala de aula, alterações foram propostas e paulatinamente imagens fotográficas do local estudado foram incluídas nos painéis, em consonância com um refinamento do problema a ser abordado, as diferentes maneiras de sentar. No entanto, apenas no quinto painel aparecem imagens realizadas pela própria equipe, durante pesquisa de campo. $\mathrm{O}$ ambiente do campus levou a equipe a tomar decisões quanto aos materiais a serem utilizados, incorporando referências culturais da região ao produto final para o qual foi produzido modelo físico em escala. As imagens do modelo demonstram as diferentes possibilidades de uso.

Figura 6- Painel 5 - posições de sentar no espaço estudado e paleta de cores; fotografias do modelo.
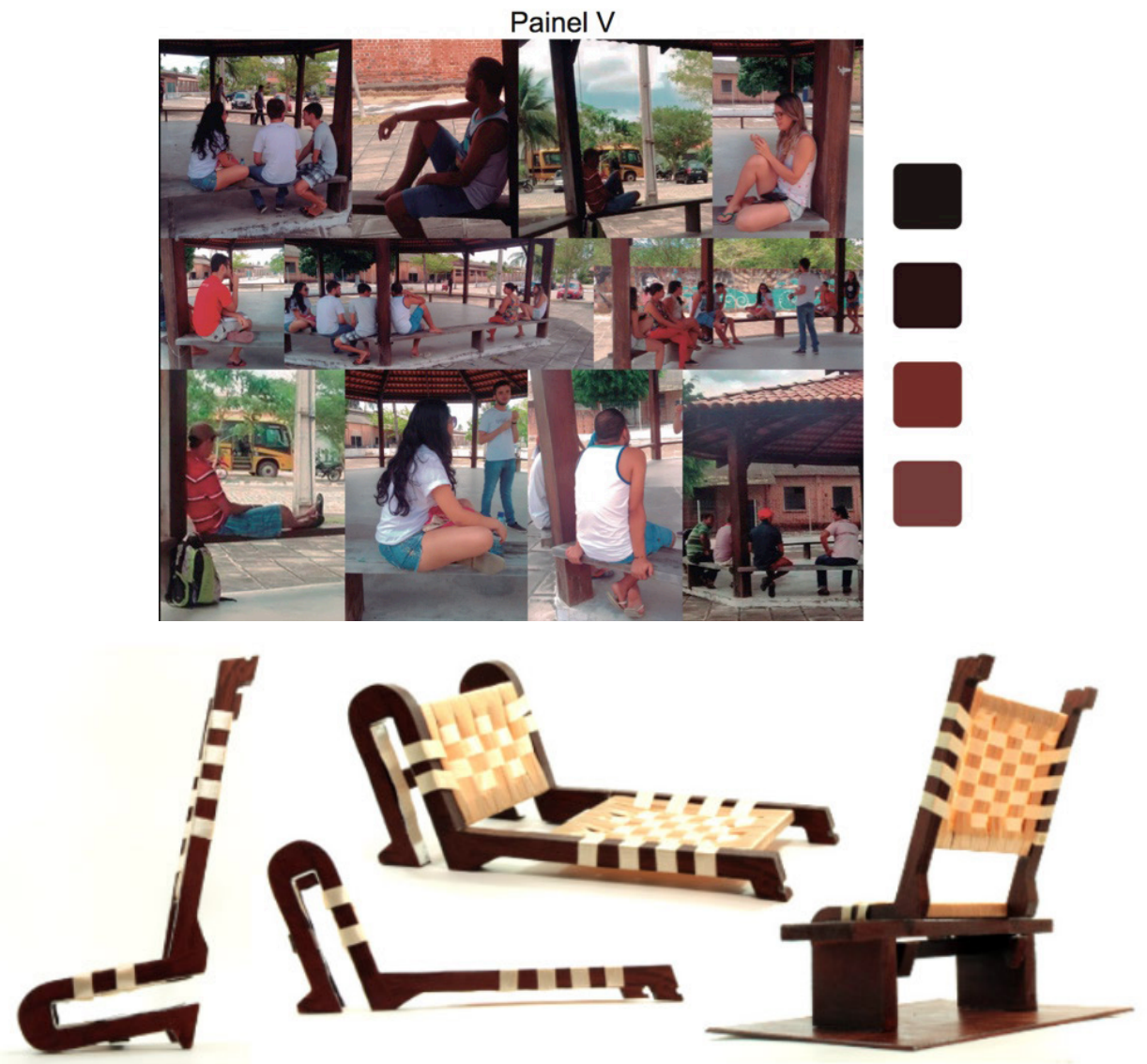

Fonte: Elaborado pelos autores.

\section{OUTROS OLHARES}

Experiências projetuais nos oferecem interessantes oportunidades para explorar nossas capacidades de receber, processar e solucionar demandas aplicando os conhecimentos adquiridos no campo do Design e áreas correlatas ou complementares. Por meio dessas experiências é possível também ampliar nossas percepções em diferentes contextos, especialmente quando nos são colocadas demandas reais, ou próximas à realidade, nas quais pode-se perceber 
a importância em se aplicar os métodos de forma comprometida com o resultado esperado. Além disso, observa-se que uma vez colhidos bons resultados, desperta-se o interesse pela continuidade na busca por melhorias e até mesmo comparações com experiências anteriores. Ainda que sejam muitos os desafios em projetos interdisciplinares, permanecem o desejo e a necessidade de realizar mais experiências compartilhadas, ampliando o espectro de ações no âmbito do curso.

Nesse sentido a experiência aqui relatada vem se desdobrando em uma nova edição de projeto interdisciplinar, agora denominado projeto integrado, para proporcionar aos participantes (discentes e docentes), uma visão sistêmica do processo projetual, por meio da colaboração mútua entre as diferentes áreas (disciplinas) que compõem o quarto período do curso de Design, além de duas disciplinas optativas. Como forma de potencializar recursos e as atividades, identificados na experiência relatada como frágeis para a obtenção de êxito nos projetos, optamos pelo uso do Guia de Orientação para Desenvolvimento de Projetos (GODP), metodologia centrada no usuário desenvolvida pelo Núcleo de Gestão do Design da Universidade Federal de Santa Catarina (UFSC), de autoria da professora Giselle Schmidt Alves Díaz Merino (2016). Tendo sido elaborado com base em experiências e princípios oriundos de métodos consagrados, o referido método, evidencia-se como uma alternativa interessante. Atribuímos isto, especialmente devido às adaptações trazidas ao contexto acadêmico, oferecendo flexibilidade no uso de ferramentas e técnicas de análise e síntese em busca de soluções inovadoras tendo o usuário como figura central do processo.

Percebemos ao longo do experimento a necessidade de ampliar os estudos e referências da relação entre estética e atividade projetual, assim, a pesquisa realizada pelo professor Célio Teodorico dos Santos, como tese de doutoramento, passou a integrar nossas reflexões. A proposta do autor coadunase com nossa defesa da importância da função estética no desenvolvimento de produtos, propondo a aplicação do Modelo de Abordagem do Design para a Estética (MADFAe) em projetos de produtos. Apresentado como um "modelo aberto", é indicado pelo autor como passível de utilização junto a "outros métodos, ferramentas e documentos de apoio que a equipe de projeto resolver utilizar, pode ser integrado ao modelo proposto sem afetar a qualidade final das informações e do objetivo definido". (SANTOS, 2009, p. 93).

O interesse pelo campo estético e suas aplicações ao Design, apontaram para a importância das referências visuais, especialmente nas etapas de coleta e análise de informações no processo de projetação. Por este motivo, no experimento realizado, grande interesse recaiu sobre mapas mentais e painéis visuais, que se apresentaram como ferramentas relevantes nas definições projetuais. Neste percurso, o texto de Daniela Campos (2015), que propõe o uso do Atlas como ferramenta para elaboração de painéis visuais, vem se tornando aliado de nossas reflexões e experimentações. Ao demonstrar o interesse em dialogar com autores presentes também em nossos estudos, como Aby Warburg e Walter Benjamin, seu texto, utilizado inicialmente apenas como indicação de 
leitura, vem sendo incorporado ao debate em sala de aula.

Na tarefa de estimular jovens estudantes de Design a fazerem uso consciente da função estética dos produtos (em toda sua amplitude) no ato de projetação mais uma questão se colocou: como acessar, no micro espaço das disciplinas ministradas, dados empíricos e relevantes, concernentes aos valores estéticos dos usuários? E mais, como equaciona-los e trata-los para que sejam incluídos no ato da projetação? Estas duas questões não foram plenamente respondidas na experimentação a que nos propomos com os estudantes, no entanto, aborda-las foi fundamental para ajudar-nos a refletir acerca do potencial diálogo desses dois campos do saber, Estética e Design, no desenvolvimento de produtos.

\section{REFERÊNCIAS}

BAXTER, Mike. Projeto de produto: guia prático para o desenvolvimento de novos produtos. São Paulo: Edgard Blücher.1998.

BENJAMIN, Walter et al. Benjamin e a obra de arte: técnica, imagem, percepção. Tradução de Marijane Lisboa e Vera Ribeiro. Rio de Janeiro: Contraponto, 2012.

BONSIEPE, Gui. Design: do material ao digital. Tradução de Cláudio Dutra. Florianópolis: FIESC/IEL, 1997.

CAMPOS, Daniela Queiroz. O atlas como método para o design: o uso do atlas e dos conceitos de montagem como ferramenta metodológica par a pesquisa visual. E-Revista Logo, Florianópolis, v. 4, n. 1, p. 91-104, 2015.

DIDI-HUBERMAN, Georges. Diante da imagem. São Paulo: Editora 34, 2013.

FAGGIANI, Kátia. O poder do design: da ostentação à emoção. Brasília: Thesaurus, 2006.

FORTY, Adrian. Objetos do desejo: design e sociedade desde 1750. Tradução de Pedro Maria Soares. São Paulo: Cosac Naify, 2007.

GOMBRICH, E. H. Meditações sobre um cavalinho de pau e outros ensaios sobre a teoria da arte. São Paulo: Edusp. 1999.

HAAR, Michel. A obra de arte. Rio de Janeiro: Difel, 2000.

KORICHI, Mériam. Notions d'esthétique: anthologie. Paris: Floio Plus Philosophie, 2007.

LÖBACH, Bernd. Design industrial: bases para a configuração dos produtos industriais. Tradução de Freddy Van Camp. São Paulo: Edgard 
Blücher, 2001.

MERINO, Giselle Schmidt Alves Díaz. GODP: guia de orientação para desenvolvimento de projetos: uma metodologia de design centrado no usuário. Florianópolis: NGD/ UFSC, 2016.

SANTOS, Célio Teodorico dos. Requisitos de linguagem do produto: uma proposta de estruturação para as fases iniciais do PDP. 2009. 205 f. Tese (Doutorado em Engenharia Mecânica) - Universidade Federal de Santa Catarina, Florianópolis, 2009.

VIANNA, Maurício et al. Design thinking: inovação em negócios. Rio de Janeiro: MJV Press, 2012.

WARBURG, Aby. Atlas mnemosyne. Madrid: Akal, 2010. (Arte y estética, n. 77). 